\title{
A Novel Model of the Ideal Point Method Coupled with Objective and Subjective Weighting Method for Evaluation of Surrounding Rock Stability
}

\author{
Yingchao Wang, ${ }^{1,2}$ Ning Zhao, ${ }^{2}$ Hongwen Jing, ${ }^{1,2}$ Bo Meng, ${ }^{2}$ and Xin Yin ${ }^{2}$ \\ ${ }^{1}$ State Key Laboratory for Geomechanics and Deep Underground Engineering, China University of Mining \& Technology, \\ Xuzhou 221116, China \\ ${ }^{2}$ School of Mechanics \& Civil Engineering, China University of Mining \& Technology, Xuzhou 221116, China \\ Correspondence should be addressed to Yingchao Wang; wych12345678@126.com
}

Received 9 August 2016; Accepted 24 November 2016

Academic Editor: Suzanne M. Shontz

Copyright @ 2016 Yingchao Wang et al. This is an open access article distributed under the Creative Commons Attribution License, which permits unrestricted use, distribution, and reproduction in any medium, provided the original work is properly cited.

\begin{abstract}
The classification of surrounding rock stability is the critical problem in tunneling engineering. In order to decrease engineering disasters, the surrounding rock stability should be accurately evaluated. The ideal point method is applied to the classification of surrounding rock stability. Considering the complexity of surrounding rock classification, some factors such as rock uniaxial compressive strengthen, integrality coefficient of rock mass, the angle between tunnel axis and the main joint, joints condition, and seepage measurement of groundwater are selected as evaluation indices. The weight coefficients of these evaluation indices are determined by the objective and subjective weighting method, consisting with the delphi method and the information entropy theory. The objective and subjective weighting method is exact and reliable to determine the weights of evaluation indices, considering not only the expert's experiences, but also objectivity of the field test data. A new composite model is established for evaluating the surrounding rock stability based on the ideal point method and the objective and subjective weighting method. The present model is applied to Beigu mountain tunnel in Jiangsu province, China. The result is in good agreement with practical situation of surrounding rock, which proves that the ideal point method used to classify the surrounding rock in tunnels is reasonable and effective. The present model is simple and has very strong operability, which possesses a good prospect of engineering application.
\end{abstract}

\section{Introduction}

The classification of surrounding rock stability is critical for the design and construction of tunnels. The construction methods and support structures are not rational without an accurate classification of surrounding rock stability. Meanwhile, it is also a critical engineering question for the crisis management of geological hazards [1]. Collapse frequently occurs in the construction of tunnels, which leads to great economic loss and heavy casualties. Therefore, it has great realistic significance to do research on the evaluation of surrounding rock stability in tunnels.

The rock mass stability is evaluated through the determination of the grade of surrounding rock. The essence of the classification of surrounding rock is engineering analogy.
According to the classification of surrounding rock, engineers can understand the geological characteristic of rock mass and study the failure mechanism of rock mass.

The classification of rock mass stability is an ancient research issue, which is improved with the improvement of understanding on the rock mass and the accumulation of engineering experiences. A large number of scholars and engineers have been devoted to the problem for a long time. There are three type of methods for the classification of rock mass, including qualitative analysis method, quantitative analysis method, and meta-analysis method. With the development of monitoring measurement technology and rock mass mechanics, the qualitative analysis is gradually replaced by the quantitative analysis. The classification of surrounding rocks using multiple indices is instead of single index. 
In order to determine the load to the tunnel support structure, many scholars put forward lots of methods for the classification of rock mass in 1920s. Terzaghi presented the first practicable method of rock load classification system. Then, Protodyakonov coefficient $(f)$ was used to classify the grade of rock mass. After the 1950s, many methods were presented to evaluate the stability of surrounding rock, such as stand-up time classification method, RQD classification method, Q classification method, and RMR classification method. To ensure the safety of largescale tunnels and provide useful quantitative information, the rational classification of surrounding rock stability has become increasingly complex because more and more parameters have to be considered.

Recently, various improved methods such as the fuzzy sets method [2,3], artificial neural network (ANN), the fuzzy analytical hierarchy process [4], the distance discriminate analysis method [5, 6], the support vector machine method [7, 8], the automated rock classification system [9], the cloud approach [10], set pair analysis model [11], and efficacy coefficient method [12] have been proposed to classify the stability of rock mass. The above researches greatly promote the evaluation of surrounding rock stability. But every theory or method has its shortage. Some of the theories and methods cannot reveal the quantifying relation between surrounding rock and its affecting indices, while others have some limitations despite their uniqueness to deal with the problem of surrounding rock stability. For example, the accuracy of artificial neural network (ANN) cannot be promised under limited training samples. The membership degrees and weights are difficult to calculate, so the result of fuzzy mathematical theory is not convinced. So it is critical to study scientific, rational, and practical evaluation models to evaluate the stability of surrounding rock in tunneling engineering.

In the present work, based on the ideal point method, coupled with the delphi method and information entropy theory, a new model is established for the evaluation of surrounding rock stability in tunnels. The ideal point method is a generalization of discriminant analysis theory. As a comprehensive evaluation method, the ideal point method can simultaneously deal with the comprehensive evaluation of multiple factors and multiple objects. At present, the ideal point method has been applied in many fields, such as forest harvest regulation [13], stochastic multiple attribute decision [14], a power restoration strategy for the distribution network [15], environmental quality evaluation [16], and the evaluation project of land use planning [17]. With the consideration of the hydrology and the engineering geological conditions, several main influence factors were selected as evaluation indices for analysis. The weight of each index is determined by an optimal weights combination method. Coupled with the delphi method and the entropy method, the optimal weights combination method could consider both subjective and objective weight information. The delphi method can consider the experts' experience and professional knowledge, and the entropy method can dig the internal information of measured data. This optimal weights combination method can ensure the accuracy and reliability of the contribution of each index to surrounding rock stability. What is more, the established model was applied to Beigu mountain tunnel which locates at Lianyungang city, Jiangsu Province, in China. The results show that the evaluation results agree well with the practical situation. The presented model and the results could provide scientific evidence for evaluation of surrounding rock stability in tunnels.

\section{Principle of the Ideal Point Method}

2.1. Definition. The kernel of the ideal point method is to find a point which mostly approaches the ideal point with the help of a defined model. The distance between the point and the ideal point is the minimum, while the distance between the point and the anti-ideal point is the maximum.

\subsection{The Evaluation Process of the Ideal Point Method}

2.2.1. Establish Evaluation Indices Matrix. For an evaluation object $R$, assume that there are $n$ evaluation indices $\left(x_{1}, x_{2}, \ldots, x_{n}\right)$. Every index has its own objective function, such as $f_{1}(x), f_{2}(x), \ldots$, and $f_{n}(x)$. Define a vector function $F(x)=\left[f_{1}(x), f_{2}(x), \ldots, f_{n}(x)\right]$. The weights of evaluation indices are, respectively, $\omega_{1}, \omega_{2}, \ldots$, and $\omega_{n}$. The evaluation indices matrix, $X$, is as follows:

$$
\begin{aligned}
X & =\left\{x_{1}, x_{2}, \ldots, x_{n}\right\} \omega \\
& =\left\{x_{1}, x_{2}, \ldots, x_{n}\right\}\left[\omega_{1}, \omega_{2}, \ldots, \omega_{n}\right]^{T} .
\end{aligned}
$$

2.2.2. Establish the Ideal Point and the Anti-Ideal Point. The evaluation indices can be classified into two types of indices [16], positive indices and inverse indices. For positive indices, the bigger the positive indices are, the better the evaluation object will be. For inverse indices, the smaller the relative indices are, the better the evaluation object will be. Assuming that the values of evaluation indices change with linear law, the ideal point and anti-ideal point are as follows.

For positive indices,

$$
\begin{aligned}
& f_{i}^{*}(+)=\max f_{i}(x), \quad i=1,2, \ldots, n, \\
& f_{i}^{*}(-)=\min f_{i}(x), \quad i=1,2, \ldots, n,
\end{aligned}
$$

where $f_{i}^{*}(+)$ and $f_{i}^{*}(-)$ are, respectively, the ideal point vector and the anti-ideal point vector of $i$ th evaluation index. $f_{i}(x)$ is the value of $i$ th evaluation index.

For inverse indices,

$$
\begin{aligned}
& f_{i}^{*}(+)=\min f_{i}(x), \quad i=1,2, \ldots, n, \\
& f_{i}^{*}(-)=\max f_{i}(x), \quad i=1,2, \ldots, n .
\end{aligned}
$$

2.2.3. The Evaluation Function of the Ideal Point. The optimized solution of evaluation index is the point mostly approaching the ideal point and mostly far from the anti-ideal point. That means that the distance to ideal point is minimum $\left(\left\|f(x)-f^{*}(+)\right\| \rightarrow \min \right)$, while the distance to anti-ideal point is maximum $\left(\left\|f(x)-f^{*}(-)\right\| \rightarrow \max \right)$. The Minkowski 
distance is often used to determine the ideal point and the anti-ideal point, which is shown as follows.

The distance to the ideal point, $d_{1}$, is calculated by

$$
\begin{aligned}
d_{1} & =\left\|f(x)-f^{*}(+)\right\| \\
& =\left\{\sum_{i=1}^{n} \omega_{i}\left[\frac{\left(f_{i}(x)-f_{i}^{*}(+)\right)}{f_{i}^{*}(+)}\right]^{p}\right\}^{1 / p} .
\end{aligned}
$$

The distance to the anti-ideal point, $d_{2}$, is calculated by

$$
\begin{aligned}
d_{2} & =\left\|f(x)-f^{*}(-)\right\| \\
& =\left\{\sum_{i=1}^{n} \omega_{i}\left[\frac{\left(f_{i}(x)-f_{i}^{*}(-)\right)}{f_{i}^{*}(-)}\right]^{p}\right\}^{1 / p},
\end{aligned}
$$

where $d_{1}$ is the distance to the ideal point. $d_{2}$ is the distance to the anti-ideal point. $p$ is a parameter that can be changed according to the practical evaluation problems. When $p$ is equal to $1, d_{1}$ and $d_{2}$ are defined as hamming distance or absolute distance. When $p$ is equal to $2, d_{1}$ and $d_{2}$ are defined as Euclid distance. When $p$ approaches infinity as a limit $(p \in \propto), d_{1}$ and $d_{2}$ are defined as Chebyshev distance.

2.2.4. Calculation of the Closeness Degree for Ideal Point. The closeness degree for ideal point, $T$, is calculated by

$$
T=\frac{d_{2}}{d_{1}+d_{2}},
$$

where $0 \leq T \leq 1$. The bigger the value of $T$ is, the better the evaluation object will be. Meanwhile, the bigger the value of $T$ is, the smaller the distance to ideal point and the bigger the distance to anti-ideal point will be.

\section{Principle of the Objective and Subjective Weighting Method}

Weights reflect the relative importance of indices in the evaluation process. There are two types of methods to determine the weights: one is objective methods, including the delphi method, analytic hierarchy process, etc.; the other is subjective methods, including entropy method, principal component analysis, etc. The accuracy of subjective methods is determined by the experiences and judging ability, while the accuracy of objective methods depends on the reliability of measuring data. In order to accurately calculate the weights of evaluation indices and make sure of the effectiveness of the classification of surrounding rock stability, an optimal weights method is presented considering both subjective and objective weight information. The delphi method is used to determine the subjective weight and the entropy method is used to determine the objective weight.

3.1. Principle of the Delphi Method. The delphi method is a structured communication technique or method, originally developed as a systematic, interactive forecasting method which relies on a panel of experts. The process of the delphi method is as follows: (1) select the experts of the relative research field, (2) design forms, (3) seek the opinions of experts, and (4) process the data and determine the weights. The subjective weights can be calculated as follows:

$$
\begin{aligned}
H & =\sum_{i=1}^{n} \frac{a_{i}}{s}, \\
\delta^{2} & =\frac{1}{s-1} \sum_{i=1}^{n}\left(a_{i}-H\right)^{2}, \\
\omega_{i a} & =\frac{H_{i}}{\sum_{i=1}^{n} H_{i}},
\end{aligned}
$$

where $H$ is average value of all evaluation values, $\delta^{2}$ is variance which reflects the degree of decentralization of experts' opinions, $s$ is the numbers of experts, $a_{i}$ is the evaluation value of the $i$ th expert, $a_{i} \in[1,10]$, and $\omega_{i a}$ is the subject weight of the $i$ th evaluation index.

3.2. Principle of the Entropy Method. The proper assessment of attribute weights plays an essential role in the process because the variation of weight values may result in different results of alternatives [18]. There are many methods to determine the weights [19], which can be divided into two categories: the first one is subjective method, for example, expert assessment method, analytic hierarchy process, and experience method. The second one is objective method, for example, entropy analysis and principal components analysis. Due to the effect of individual sense, subjective method could not determine the weights for the evaluation indices objectively and exactly. Therefore, entropy method was selected for objective weight determination in this work.

Entropy is a thermodynamic property that can be used to determine the energy available for useful work in a thermodynamic process. It is also a measure of the tendency of a process and an expression of disorder or randomness. Then entropy is introduced into information theory by Shannon, C. E., an American mathematician. Shannon developed information entropy as a measure for the uncertainty in a message while essentially inventing the field of information theory. Subsequently, entropy has been widely used in many fields, such as in the social field, in the economic and financial field, and in the engineering and technology field. In information theory, entropy is a measure of the uncertainty associated with a random variable [19].

For a random variable $X$ with $n$ outcomes $\left\{x_{i}: i=\right.$ $1, \ldots, n\}$, the Shannon entropy, a measure of uncertainty (see further below) and denoted by $H(x)$, is defined as

$$
H(x)=-\sum_{i=1}^{n} p\left(x_{i}\right) \log _{b} p\left(x_{i}\right),
$$

where $p\left(x_{i}\right)$ is the probability mass function of outcome $x_{i}$ and $b$ is the base of the logarithm used.

Information entropy (entropy for short) is the measurement of the disorder degree of a system. It can measure the amount of useful information with the data provided. On the one hand, when the difference of the value among the evaluated objects on the same index is high, while the 
entropy is small, it illustrates that this index provides more useful information, and the weight of this index should be set correspondingly high. On the other hand, if the difference is smaller and the entropy is higher, the relative weight would be smaller [19], assuming that there was an index system, combined with $m$ indices, which could be used to evaluate $n$ objects. And $x_{i j}$ is the $i$ th index value of the $j$ th object. Then the original matrix for evaluation is as follows:

$$
X=\left(x_{i j}\right)_{m \times n} .
$$

Linear method is used to make the indices standardized. The optimal values of each indices, $x_{j}^{*}=\max _{i}\left\{x_{i j}\right\}$, are selected and standardized. And a new evaluation matrix is received:

$$
Y=\left(y_{i j}\right)_{m \times n}=\frac{x_{i j}}{x_{i}^{*}} .
$$

The entropy value of $i$ th evaluation index is

$$
e_{i}=-k \sum_{j=1}^{n} f_{i j} \ln f_{i j}
$$

where $f_{i j}=y_{i j} / \sum_{j=1}^{n} y_{i j}, k=1 / \ln n, k>0, e_{i} \geq 0$.

Since $0 \leq f_{i j} \leq 1$ and $0 \leq e_{i j} \leq 1$, then, the total entropy value of all indices can be calculated as

$$
E=\sum_{i=1}^{m} e_{i}=-k \sum_{i=1}^{m} \sum_{j=1}^{n} \frac{y_{i j}}{\sum_{j=1}^{n} y_{i j}}\left(\ln y_{i j}-\ln \sum_{j=1}^{n} y_{i j}\right) .
$$

The deviation degree of $i$ th index is defined as $d_{i}$, which is equal to $1-e_{i}$. The entropy weight of $i$ th index can be calculated as

$$
\omega_{i}=\frac{d_{i}}{\sum_{i=1}^{m} d_{i}}=\frac{1-e_{i}}{m-E} .
$$

3.3. Determination of Comprehensive Weights. The delphi method can consider the experts' experience and professional knowledge but has the shortcoming of subjective supposition and the results are greatly influenced by personal judging ability. The entropy method can dig the internal information of measured data and the evaluation results are objective, but the experiences and suggestions of experts cannot be considered. Combining the delphi method and the entropy method, the comprehensive weight of each index, $\omega_{i}$, can be calculated as follows:

$$
\omega_{i}=\beta \omega_{i a}+(1-\beta) \omega_{i b}
$$

where $\omega_{i}$ is the comprehensive weight determined by the objective and subjective weighting method. The value of $\omega_{i}$ changes with the changes of $\beta$. When $\beta=1$, the comprehensive weight is equal to subjective weight $\left(\omega_{i a}\right)$. When $\beta=0$, the comprehensive weight is equal to objective weight $\left(\omega_{i b}\right)$. Normally, the subjective weight is equally important as objective weight, so the value of $\beta$ is selected as 0.5 .

\section{Development of Surrounding Rock Stability Evaluation Model Based on the Ideal Point Analysis}

4.1. Analysis on Evaluation Indices and Evaluation System. The selection of evaluation indices is important for classification of surrounding rock stability [1]. Surrounding rock stability in tunneling engineering is influenced by many factors, including rock mass characteristics, underground water, the state of stress, joint plane, etc. When considering the selection of the indices, it is necessary for the factors to satisfy the following requirements: on the one hand, they must be scientific and effective and could reflect the essence of rock mass. The selected indices are valid with good repeatability. On the other hand, the factors should be simple and practicable and could be determined easily. According to previous researches $[2,11,20]$, some factors such as rock uniaxial compressive strengthen $\left(R_{c}\right)$, integrality coefficient of rock mass $\left(K_{v}\right)$, the angle between tunnel axis and the main joint $(\theta)$, joints condition $\left(S_{s}\right)$, and seepage measurement of groundwater $(W)$ are selected as evaluation indices. It is shown that these five indices can comprehensively reflect the surrounding rock stability in tunneling engineering. Then the evaluation index system of surrounding rock stability was established. The classification standard of surrounding rock stability was presented in Table 1 [11].

\subsection{Determination of Weights with the Delphi Method and the Entropy Method}

4.2.1. The Calculation of Subjective Weight. Based on the principle of the delphi method, and according to (1)-(6), the subjective weights of evaluation indices of surrounding rock stability are calculated, and the results are shown in Table 2.

4.2.2. The Calculation of Objective Weight. Based on the principle of information entropy, the objective weight coefficients of evaluation indices of surrounding rock stability are calculated. According to (8)-(13), the entropy, deviation degree, and entropy weight are obtained, as shown in Table 3.

4.2.3. The Calculation of Comprehensive Weights. Combing with the delphi method and the entropy method, the comprehensive weight coefficients are obtained with the assumption that the subjective weight is equally important as objective weight. The results are shown in Table 4.

4.3. Determination of the Ideal Point Matrix and Anti-Ideal Point Matrix. In the evaluation index system of surrounding rock stability, rock uniaxial compressive strengthen $\left(R_{c}\right)$, integrality coefficient of rock mass $\left(K_{v}\right)$, the angle between tunnel axis and the main joint $(\theta)$, and joints condition $\left(S_{s}\right)$ were regarded as positive indices. The bigger these positive indices are, the higher the grade of surrounding rock is. Meanwhile, seepage measurement of groundwater $(W)$ was regarded as inverse index. The smaller the inverse index is, the higher the grade of surrounding rock is. According to (4), (5) and the classification standard of surrounding rock 
TABLE 1: Classification standard of surrounding rock stability.

\begin{tabular}{lcccc}
\hline Stability class & $R_{c} / \%$ & $K_{v}$ & $S_{s}$ & $W /\left(\mathrm{L} \cdot \mathrm{min}^{-1}\right)$ \\
\hline I (very good) & $250 \sim 300$ & $0.75 \sim 1.0$ & $9 \sim 10$ & $0 \sim 5$ \\
II (good) & $100 \sim 250$ & $0.55 \sim 0.75$ & $7 \sim 9$ & $5 \sim 10$ \\
III (fair) & $50 \sim 100$ & $0.35 \sim 0.55$ & $4 \sim 7$ & $10 \sim 25$ \\
IV (poor) & $25 \sim 50$ & $0.15 \sim 0.35$ & $2 \sim 4$ & $25 \sim 125$ \\
V (very poor) & $1 \sim 25$ & $0 \sim 0.15$ & $0 \sim 2$ & $125 \sim 250$ \\
\hline
\end{tabular}

TABLE 2: The subjective weight coefficients of evaluation indices.

\begin{tabular}{|c|c|c|c|c|c|}
\hline Evaluation indices & $R_{c}$ & $K_{v}$ & $S_{s}$ & $W$ & $\theta$ \\
\hline$a_{1}$ & 9.0 & 8.0 & 10.0 & 7.0 & 9.0 \\
\hline$a_{2}$ & 8.0 & 10.0 & 10.0 & 8.0 & 9.0 \\
\hline$a_{3}$ & 8.0 & 9.0 & 9.0 & 7.0 & 8.0 \\
\hline$E_{i}$ & 8.667 & 9.0 & 9.667 & 7.333 & 8.667 \\
\hline$\delta^{2}$ & 0.333 & 1.0 & 0.333 & 0.333 & 0.333 \\
\hline$\omega_{i a}$ & 0.200 & 0.208 & 0.223 & 0.169 & 0.200 \\
\hline
\end{tabular}

TABLE 3: Results of entropy weigh coefficients for each evaluation index.

\begin{tabular}{|c|c|c|c|c|c|}
\hline Evaluation indices & $R_{c}$ & $K_{v}$ & $S_{s}$ & $W$ & $\theta$ \\
\hline The entropy $\left(e_{i}\right)$ & 0.9966 & 0.9401 & 0.9773 & 0.9915 & 0.9907 \\
\hline Deviation degree $\left(d_{i}\right)$ & 0.0034 & 0.0599 & 0.0227 & 0.0085 & 0.0093 \\
\hline Entropy weight $\left(\omega_{i b}\right)$ & 0.0325 & 0.5768 & 0.2191 & 0.0816 & 0.0899 \\
\hline
\end{tabular}

TABLE 4: The weights for each evaluation index based on the objective and subjective weighting methods.

\begin{tabular}{lccccc}
\hline Evaluation indices & $R_{c}$ & $K_{v}$ & $S_{s}$ & $W$ & 0 \\
\hline Subjective weight $\omega_{i a}$ & 0.200 & 0.208 & 0.223 & 0.169 & 0.200 \\
Objective weight $\omega_{i b}$ & 0.0325 & 0.5768 & 0.2191 & 0.0816 & 0.0899 \\
Comprehensive weight $\omega_{i}$ & 0.1163 & 0.3924 & 0.2211 & 0.1253 & 0.1450 \\
\hline
\end{tabular}

stability (Table 1), the ideal point matrix $\left(F^{*}(+)\right)$ and the antiideal point matrix $\left(F^{*}(-)\right)$ of surrounding rock stability are obtained as follows:

$$
\begin{aligned}
F^{*}(+) & =\left[\begin{array}{ccccc}
300 & 1.0 & 10 & 5 & 90 \\
250 & 0.75 & 9 & 10 & 80 \\
100 & 0.55 & 7 & 25 & 70 \\
50 & 0.35 & 4 & 125 & 30 \\
25 & 0.15 & 2 & 250 & 10
\end{array}\right], \\
F^{*}(-) & =\left[\begin{array}{ccccc}
250 & 0.75 & 9 & 0 & 80 \\
100 & 0.55 & 7 & 5 & 70 \\
50 & 0.35 & 4 & 10 & 30 \\
25 & 0.15 & 2 & 25 & 10 \\
1 & 0 & 0 & 125 & 0
\end{array}\right] .
\end{aligned}
$$

4.4. Computational Procedure. The presented model was developed based on Visual Basic. Firstly, the value of each evaluation index was obtained through field survey and site monitoring in tunnels. Secondly, the weights of evaluation indices were calculated based on the delphi method and the entropy method. Meanwhile, the distances to the ideal point and the anti-ideal point were determined. Finally, the closeness degree for ideal point was calculated. According to the results, a decision on the grade of surrounding rock could be provided. The computational procedure and its flow chart are presented in detail, as shown in Figure 1.

\section{Case Study}

5.1. Engineering Background. As far as the practical significance was concerned, the present method was applied in Beigu mountain tunnel, which locates at Lianyungang city, Jiangsu province, in China. Beigu mountain tunnel is the critical engineering of North Port expressway with the length of $10912 \mathrm{~km}$ and total investment of 1 billion yuan. North Port expressway is an important distributing road of seaport, which can improve the handling capacity of the Lianyungang port. Beigu mountain tunnel begins at southwestern slope of Big Coffin Mountain and terminates at east slope of Huangshizui.

Beigu mountain tunnel is one-way section with two separating lanes. The length of the left tunnel is $2810 \mathrm{~m}$ and 


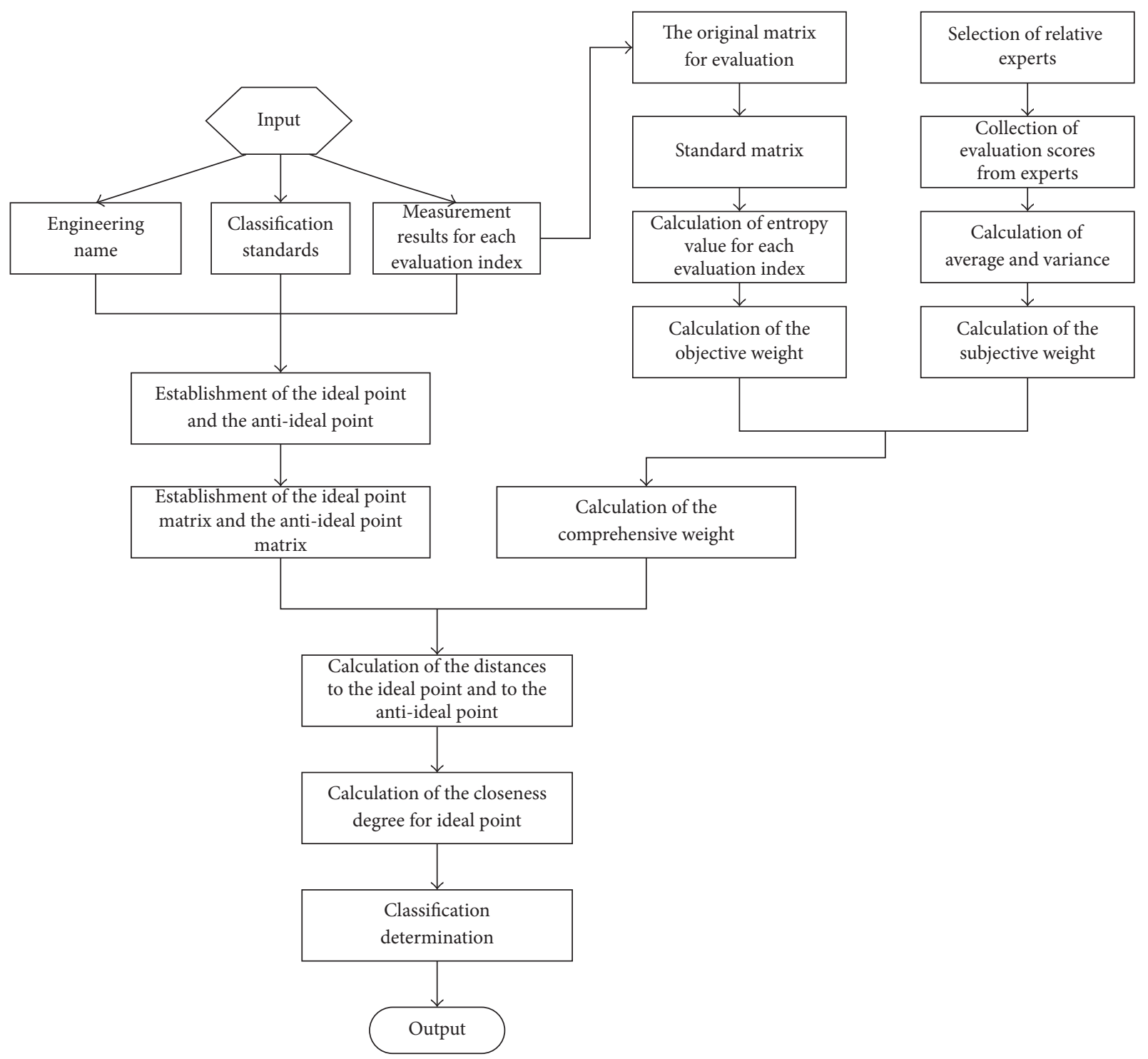

FIGURE 1: Flow chart of classification of the surrounding rock stability.

varies from $\mathrm{K} 3+330$ to $\mathrm{K} 6+140$. The length of the right tunnel is $2755 \mathrm{~m}$ and varies from $\mathrm{K} 3+305 \sim \mathrm{K} 6+060$. The clear width of the Beigu mountain tunnel is $14 \mathrm{~m}$ with the height of $5.0 \mathrm{~m}$. The maximum overburden thickness for the tunnel is $338 \mathrm{~m}$. At the tunnel entrance and the tunnel exit, the distance between the left tunnel and the right tunnel are, respectively, $10.0 \mathrm{~m}$ and $12.0 \mathrm{~m}$. Along the direction of tunnel axis, the maximum distance between the left tunnel and the right tunnel is $37.0 \mathrm{~m}$. The New Austrian Tunneling Method (NATM) was used for the construction of Beigu mountain tunnel. The cross-section of the tunnel was three-centered circular arch. Double-lining was applied for the support systems, including the primary support and the secondary lining.

Beigu mountain tunnel goes through the complicated geological environment. The surface layer consists of the completely weathered welded tuff and the forth loose covering layer (Figure 2(a)), including silty clay with some gravel. The bottom layer is basement rock, which belongs to metamorphic rock of Yuntai formation. Beigu mountain tunnel is constructed in mica schist, chlorite schist, and leptynite (Figures 2(b), 2(c), and 2(d)). The compressive strengths of mica schist and chlorite schist are low, and their strength degrades when mixing with water. Due to the low self-bearing capacity of surrounding rock, collapse and large deformation easily occur in the construction of the tunnel, which can result in personal injury or even death to technical staffs and construction workers. Moreover, there are many buildings near the axis of Beigu mountain tunnel, including five military caves, two bridges, high-grade villas, barracks of the army and many civil house (Figure 3 ). To ensure the safety of the tunnel and surrounding buildings, it is vital to do researches on the classification of surrounding rock of Beigu mountain tunnel. 


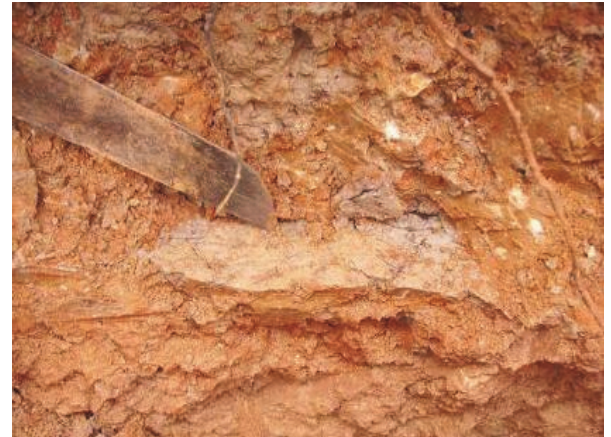

(a) The forth loose covering layer

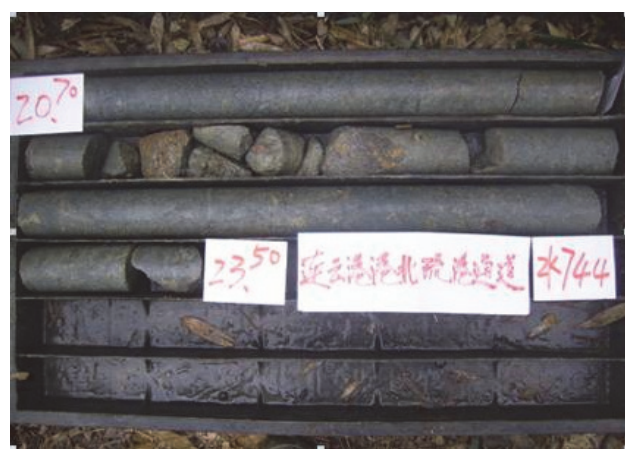

(c) Mica schist

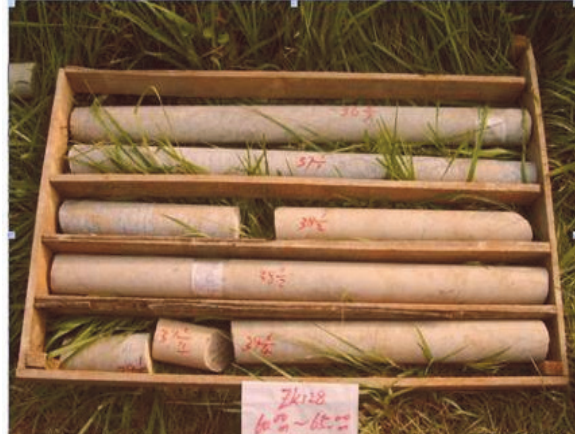

(b) Leptynite

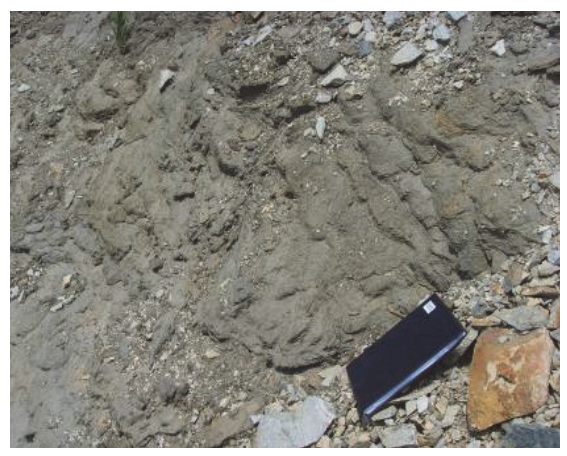

(d) Chlorite schist

FIgURE 2: The complex lithologies of Beigu mountain tunnel.

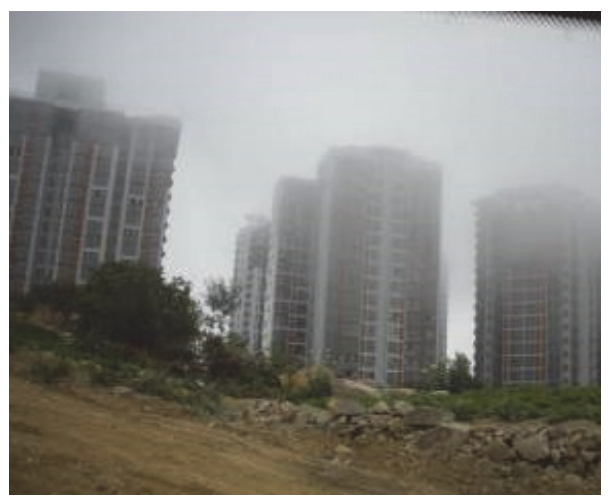

(a) High-rise buildings

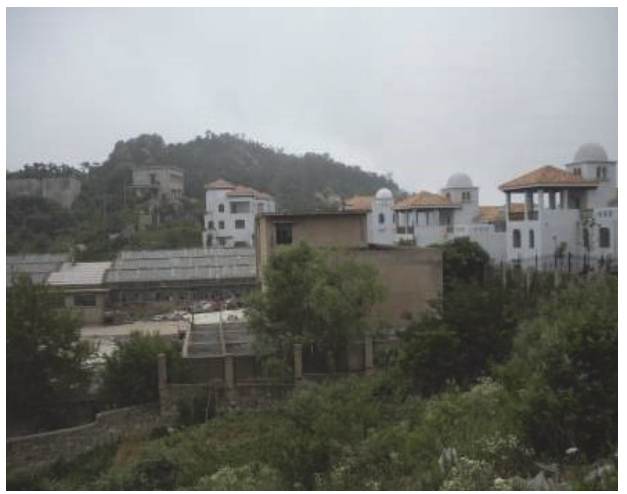

(b) Villas

FIGURE 3: Surrounding buildings near Beigu mountain tunnel.

5.2. Evaluation of Surrounding Rock Stability in the Beigu Mountain Tunnel. In the Beigu mountain tunnel, K4+100 $\mathrm{K} 4+130, \mathrm{~K} 4+490 \sim \mathrm{K} 4+520, \mathrm{~K} 4+550 \sim \mathrm{K} 4+580$, and $\mathrm{K} 5+100 \sim$ $\mathrm{K} 5+130$ were selected as evaluation objects in Beigu mountain tunnel. The values of evaluation indices are presented in Table 5. The selected samples are mainly intermediary weathered leptynite and intercalated with chlorite schist. The rock is very fragmented, lacking in integrity and stability. There are many low-resistivity abnormal zone of geophysical prospecting and water conductive faults near the tunnel axis. The groundwater belongs to the type of fracture water in bedrock. In the construction of Beigu mountain tunnel, water rushes from the exposed fissure. The great inflow of water into tunnel is unfavorable to the stability of surrounding rock.

Based on the present model, the closeness degrees of the investigated objects to the ideal point were obtained. According to the maximum subordination principle, the maximum closeness degree corresponds to the grade of surrounding rock stability. The grades of surrounding rock stability were obtained in Beigu mountain tunnel, as shown in Table 6. The results can be described in detail as follows:

(1) The closeness degrees of sample $1(\mathrm{~K} 4+100 \sim \mathrm{K} 4+130)$ to the ideal point were $T(\mathrm{I})=0.3041, T(\mathrm{II})=0.3729$, $T($ III $)=0.1751, T(I V)=0.4958$, and $T(V)=0.4740$. 
TABLE 5: Original data of surrounding rock in Beigu mountain tunnel.

\begin{tabular}{|c|c|c|c|c|c|c|}
\hline Sample & $\begin{array}{l}\text { Position in Beigu } \\
\text { mountain tunnel }\end{array}$ & $R_{c} / \%$ & $K_{v}$ & $S_{s}$ & $W /\left(\mathrm{L} \cdot \mathrm{min}^{-1}\right)$ & $\theta /^{\circ}$ \\
\hline 1 & $\mathrm{~K} 4+100 \sim \mathrm{K} 4+130$ & 61.8 & 0.33 & 2.8 & 18 & 33 \\
\hline 2 & $\mathrm{~K} 4+490 \sim \mathrm{K} 4+520$ & 64.9 & 0.27 & 3.0 & 27 & 28 \\
\hline 3 & $\mathrm{~K} 4+550 \sim \mathrm{K} 4+580$ & 74.5 & 0.67 & 4.6 & 20 & 43 \\
\hline 4 & K5+100 K5+130 & 78.3 & 0.72 & 5.0 & 23 & 39 \\
\hline
\end{tabular}

TABLE 6: The closeness degree of surrounding rock at selected tunnel section to I-V standard ideal point and the judgment of surrounding rock classification.

\begin{tabular}{|c|c|c|c|c|c|c|c|}
\hline \multirow{2}{*}{ Sample } & \multicolumn{5}{|c|}{ The closeness degree for ideal point } & \multirow{2}{*}{$\begin{array}{c}\text { Results of } \\
\text { proposed model }\end{array}$} & \multirow{2}{*}{$\begin{array}{c}\text { Actual grade of } \\
\text { surrounding rock }\end{array}$} \\
\hline & $T_{\mathrm{I} i}$ & $T_{\mathrm{II} i}$ & $T_{\mathrm{III} i}$ & $T_{\mathrm{IV} i}$ & $T_{\mathrm{V} i}$ & & \\
\hline 1 & 0.3041 & 0.3729 & 0.1751 & 0.4958 & 0.4740 & IV & IV \\
\hline 2 & 0.2334 & 0.3816 & 0.1926 & 0.4471 & 0.4660 & $\mathrm{~V}$ & $\mathrm{~V}$ \\
\hline 3 & 0.2241 & 0.3531 & 0.5412 & 0.5951 & 0.5172 & IV & IV \\
\hline 4 & 0.1947 & 0.3784 & 0.5542 & 0.5919 & 0.5199 & IV & IV \\
\hline
\end{tabular}

$T_{\mathrm{II} i}, T_{\mathrm{II} i}, T_{\mathrm{III} i}, T_{\mathrm{IV} i}$, and $T_{\mathrm{V} i}$ are, respectively, the closeness degrees of the $i$ th sample to I-V standard ideal point.

The greatest closeness degree was 0.4958 under grade IV. As a result, the classification of sample $1(\mathrm{~K} 4+100 \sim$ $\mathrm{K} 4+130$ ) was regarded as grade IV.

(2) The closeness degrees of sample $2(\mathrm{~K} 4+490 \sim \mathrm{K} 4+520)$ to the ideal point were $T(\mathrm{I})=0.2334, T(\mathrm{II})=0.3816$, $T($ III $)=0.1926, T(I V)=0.4471$, and $T(\mathrm{~V})=0.4660$. The greatest closeness degree was 0.4660 under grade $\mathrm{V}$. As a result, the classification of sample 2 (K4+490 $\mathrm{K} 4+520$ ) was regarded as grade $\mathrm{V}$.

(3) The closeness degrees of sample $3(\mathrm{~K} 4+550 \sim \mathrm{K} 4+580)$ to the ideal point were $T(\mathrm{I})=0.2241, T(\mathrm{II})=0.3531$, $T(\mathrm{III})=0.5412, T(\mathrm{IV})=0.5951$, and $T(\mathrm{~V})=0.5172$. The greatest closeness degree was 0.5951 under grade IV. As a result, the classification of sample 3 (K4+550 $\mathrm{K} 4+580$ ) was regarded as grade IV.

(4) The closeness degrees of sample $4(\mathrm{~K} 5+100 \sim \mathrm{K} 5+130)$ to the ideal point were $T(\mathrm{I})=0.1947, T(\mathrm{II})=0.3784$, $T($ III $)=0.5542, T($ IV $)=0.5919$, and $T(\mathrm{~V})=0.5199$. The greatest closeness degree was 0.5919 under grade IV. As a result, the classification of sample $4(\mathrm{~K} 5+100 \sim$ $\mathrm{K} 5+130$ ) was regarded as grade IV.

It was found from Table 6 that the results determined were in good agreement with the surrounding rock grade of practical engineering site. It suggests that this proposed model is valid to evaluate the stability of surrounding rock in tunneling engineering. This method may offer a more quantitative measure of surrounding rock stability because it can depict the closeness degree that an object to the ideal point. Therefore, the coupling model with the ideal point method, delphi method, and information entropy theory is feasible for surrounding rock stability evaluation. Meanwhile, the present method could also provide results with relative high accuracy. The model is also simple, practical, and effectively manipulated for the construction of tunnels. In addition, the present method can be extended for other assessments.

\section{Conclusions}

The classification of surrounding rock stability is critical for the design and construction of tunnels. The construction methods and support structures are not rational without an accurate classification of rock mass stability. In this work, a novel model of the ideal point method coupled with the objective and subjective weighting method was presented to analyze surrounding rock stability in tunnels. As a comprehensive evaluation method, the ideal point method can simultaneously deal with the comprehensive evaluation of multiple factors and multiple objects. It could provide accurate evaluation values in the form of the closeness degree for ideal point with the consideration of the main influence factors. Moreover, an optimal weights combination method, coupled with the delphi method and the entropy method, is presented considering both subjective and objective weight information. The delphi method can consider the experts' experience and professional knowledge, and the entropy method can dig the internal information of measured data. This optimal weights combination method can ensure the accuracy and reliability of the contribution of each index to surrounding rock stability. Furthermore, the closeness degree for ideal point was presented to specify the grade of surrounding rock stability based on the distances to the ideal point and to the anti-ideal point. The proposed model was applied in Beigu mountain tunnel in Jiangsu province, China. The evaluation results were compared with actual findings in engineering site, and good agreement was obtained. The results show that the proposed method of this work is valid to predict the classification of surrounding rock stability. It could provide the credible evaluation results for 
the construction methods and support structures of tunnels. Moreover, it is feasible and effective and could make up for the shortcoming of traditional evaluation methods and could provide a brand new way for other engineering applications.

\section{Competing Interests}

The authors declare that there are no competing interests regarding the publication of this paper.

\section{Acknowledgments}

Financial supports from the National Basic Research Program of China (973 Program) (no. 2013CB036003), the National Natural Science Foundation of China (no. 51309222, no. 41572263, and no. 51504247), and the Specialized Research Fund for the Doctoral Program of Higher Education (no. 20130095120016) are sincerely acknowledged.

\section{References}

[1] M. Wang, X. Xu, J. Li, J. Jin, and F. Shen, "A novel model of set pair analysis coupled with extenics for evaluation of surrounding rock stability," Mathematical Problems in Engineering, vol. 2015, Article ID 892549, 9 pages, 2015.

[2] M.-W. Wang, G.-Y. Chen, and J.-L. Jin, "Risk evaluation of surrounding rock stability based on stochastic simulation of multielement connection number and triangular fuzzy numbers," Chinese Journal of Geotechnical Engineering, vol. 33, no. 4, pp. 643-647, 2011.

[3] A. Aydin, "Fuzzy set approaches to classification of rock masses," Engineering Geology, vol. 74, no. 3-4, pp. 227-245, 2004.

[4] Y.-C. Liu and C.-S. Chen, "A new approach for application of rock mass classification on rock slope stability assessment," Engineering Geology, vol. 89, no. 1-2, pp. 129-143, 2007.

[5] F. Gong and X. Li, "Application of distance discriminant analysis method to classification of engineering quality of rock masses," Chinese Journal of Rock Mechanics and Engineering, vol. 26, no. 1, pp. 190-194, 2007.

[6] W. Zhang, X.-B. Li, and F.-Q. Gong, "Stability classification model of mine-lane surrounding rock based on distance discriminant analysis method," Journal of Central South University of Technology, vol. 15, no. 1, pp. 117-120, 2008.

[7] A.-N. Jiang and X.-T. Feng, "Case-based SVM method for maximal deformation forecasting of surrounding rocks of tunnels," Journal of Northeastern University (Natural Science), vol. 25, no. 8, pp. 793-795, 2004 (Chinese).

[8] D. Qiu, S. Li, L. Zhang, and Y. Xue, "Application of GA-SVM in classification of surrounding rock based on model reliability examination," Mining Science and Technology, vol. 20, no. 3, pp. 428-433, 2010 (Chinese).

[9] R. Huang, J. Huang, N. Ju, and Y. Li, "Automated tunnel rock classification using rock engineering systems," Engineering Geology, vol. 156, pp. 20-27, 2013.

[10] J. Li, M.-W. Wang, P. Xu, and P.-C. Xu, "Classification of stability of surrounding rock using cloud model," Chinese Journal of Geotechnical Engineering, vol. 36, no. 1, pp. 83-87, 2014 (Chinese).

[11] Y.-C. Wang, X.-H. Xu, Y.-L. Liu, and L.-J. Zhou, "Set pair analysis model in surrounding rock classification of highway tunnel," Journal of Harbin Institute of Technology, vol. 43, no. 4, pp. 114-119, 2011 (Chinese).

[12] Y. Wang, H. Sun, Y. Shang, and Y. Zhang, "Application of efficacy coefficient method to instability risk early-warning of tunnel surrounding rock," Chinese Journal of Rock Mechanics and Engineering, vol. 29, no. 2, pp. 3679-3684, 2010.

[13] Q. Anchen, Z. Linsen, L. Jianguo, L. Weizhong, and C. Dinghua, "Ideal point method applied in forest harvest regulation," Journal of Forestry Research, vol. 8, no. 2, pp. 117-119, 1997.

[14] Z.-P. Fan, X. Zhang, Y. Liu, and Y. Zhang, "A method for stochastic multiple attribute decision making based on concepts of ideal and anti-ideal points," Applied Mathematics and Computation, vol. 219, no. 24, pp. 11438-11450, 2013.

[15] J. Ma, W. Ma, D. Xu, Y. Qiu, and Z. P. Wang, "A power restoration strategy for the distribution network based on the weighted ideal point method," International Journal of Electrical Power and Energy Systems, vol. 63, pp. 1030-1038, 2014.

[16] J. Wang, "Comprehensive assessment underground water quality assessment in Huaibei city area based on multiple-goal decision-making and ideal point method," Environmental Science and Management, vol. 30, no. 4, pp. 111-112, 2005.

[17] J. L. Tang, X. M. Zhao, and X. Y. Shi, "The application of the method of ideal point to the evaluation project of land use planning," Journal of Shanxi Agricultural University, vol. 25, no. 2, pp. 106-110, 2005 (Chinese).

[18] T.-Y. Chen and C.-H. Li, "Determining objective weights with intuitionistic fuzzy entropy measures: a comparative analysis," Information Sciences, vol. 180, no. 21, pp. 4207-4222, 2010.

[19] Z.-H. Zou, Y. Yun, and J.-N. Sun, "Entropy method for determination of weight of evaluating indicators in fuzzy synthetic evaluation for water quality assessment," Journal of Environmental Engineering and Science, vol. 18, no. 5, pp. 1020-1023, 2006.

[20] D. H. Qiu, J. P. Chen, J. S. Que, and P. P. An, "Evaluation of tunnel rock quality with routh sets theory and artificial neural networks," Journal of Jilin University (Earth Science Edition), vol. 38, no. 1, pp. 86-91, 2008 (Chinese). 


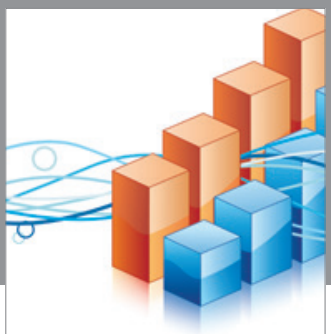

Advances in

Operations Research

vatem alat4

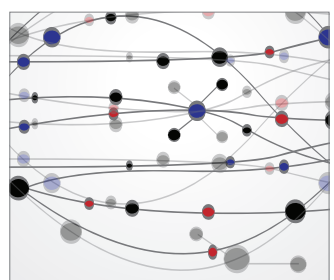

\section{The Scientific} World Journal
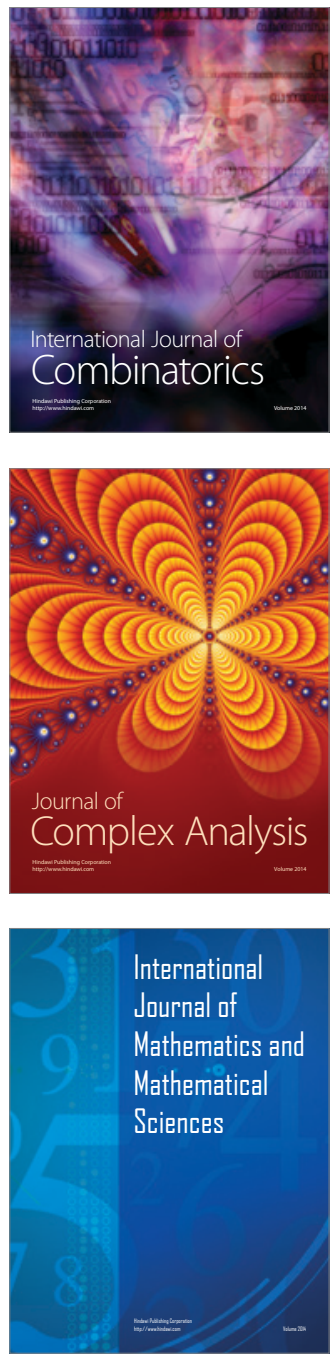
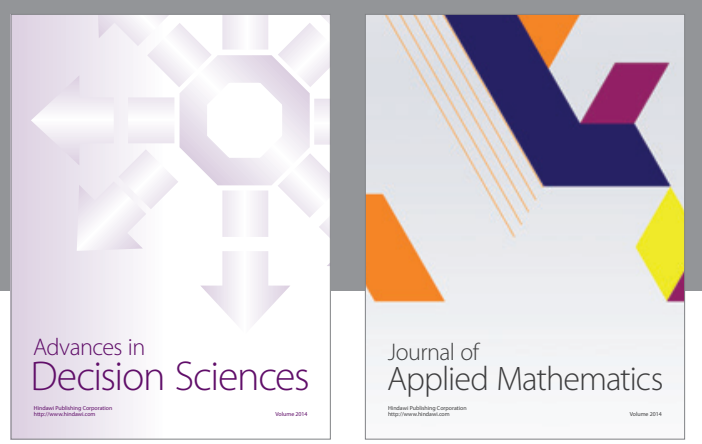

Algebra

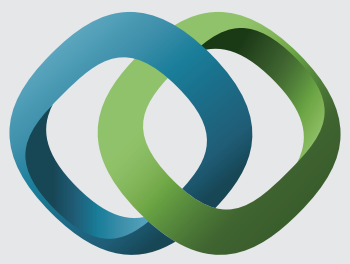

\section{Hindawi}

Submit your manuscripts at

http://www.hindawi.com
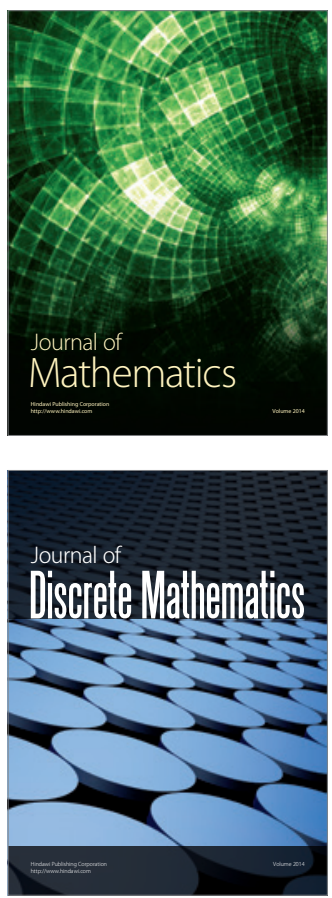

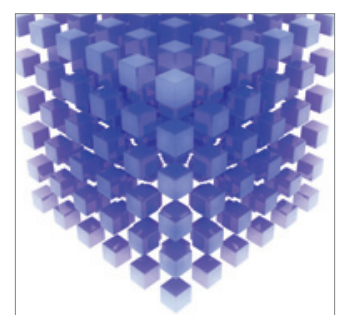

Mathematical Problems in Engineering
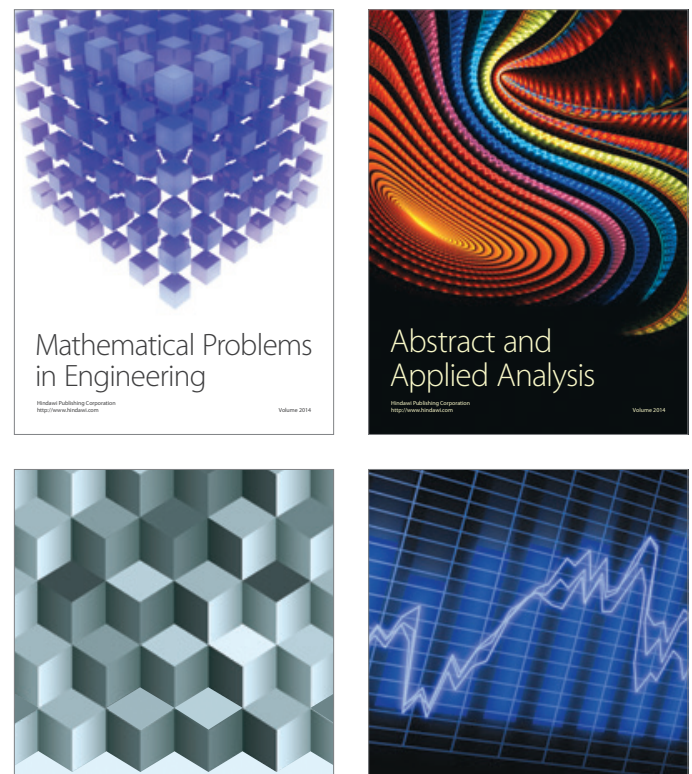

Journal of

Function Spaces

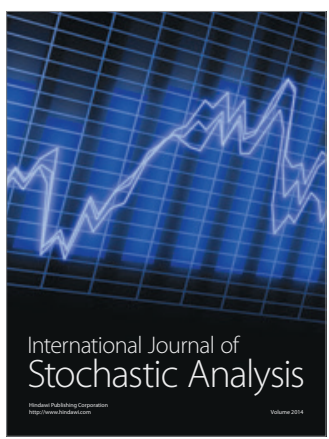

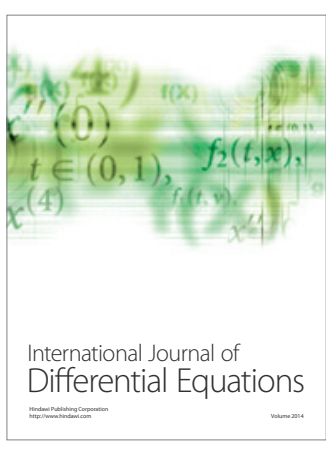
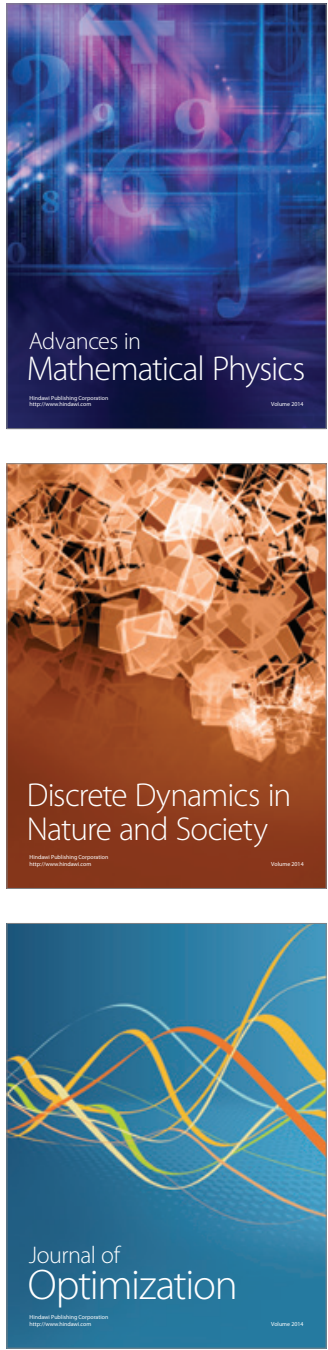